\title{
One or many? Which and how many parenting variables should be targeted in interventions to reduce children's externalizing behavior?
}

\author{
Laurie Loop ${ }^{\mathrm{a},}$,, Bénédicte Mouton ${ }^{\mathrm{a}}$, Marie Stievenart ${ }^{\mathrm{b}}$, Isabelle Roskam ${ }^{\mathrm{a}}$ \\ a Psychological Sciences Research Institute, University of Louvain, 10 place du Cardinal Mercier, 1348 Louvain-la-Neuve, Belgium \\ ${ }^{\mathrm{b}}$ Faculté de Psychologie, Logopédie et des Sciences de l'Education, University of Liege, Belgium
}

\section{A R T I C L E I N F O}

Article history:

Received 12 April 2016

Received in revised form

2 January 2017

Accepted 27 January 2017

Available online 31 January 2017

\section{Keywords:}

Parenting intervention

Externalizing behavior

Self-efficacy beliefs

Emotion coaching practices

\begin{abstract}
A B S T R A C T
This research compared the efficacy of two parenting interventions that vary according to the number and the nature of variables in reducing preschoolers' externalizing behavior (EB). The goal was to identify which parenting intervention format (one-variable versus two-variable) caused higher behavioral adjustment in children. The first was a one-variable intervention manipulating parental self-efficacy beliefs. The second was a two-variable intervention manipulating both parents' self-efficacy beliefs and emotion coaching practices. The two interventions shared exactly the same design, consisting of eight parent group sessions. Effect on children's EB and observed behaviors were evaluated through a multi-method assessment at three points (pre-test, post-test and follow-up). The results highlighted that compared to the waitlist condition, the two intervention formats tended to cause a significant reduction in children's EB reported by their parent. However, the one-variable intervention was found to lead to a greater decrease in children's EB at follow-up. The opposite was reported for children's observed behavior, which was improved to a greater extent in the two-variable intervention at post-test and follow-up. The results illustrated that interventions' format cannot be considered as purely interchangeable since their impact on children's behavior modification is different. The results are discussed for their research and clinical implications.
\end{abstract}

(C) 2017 Elsevier Ltd. All rights reserved.
Often described as difficult children, preschoolers with externalizing behavior (EB) demonstrate non-compliance, aggression, hyperactivity, inattention, impulsivity and irritability (Keenan \& Wakschlag, 2000). A clinical level of EB is the most common reason for referral to clinical services in childhood and results in important individual and social costs (Furlong et al., 2010). Its negative impact on children's social, emotional and learning skills as well as on family life has been demonstrated longitudinally (Campbell, Shaw, \& Gilliom, 2000; Fossum, Handegård, Adolfsen, Vis, \& Wynn, 2016; Wakschlag et al., 2007). It is therefore important to identify how to help children with EB and their family effectively. A large proportion of parenting interventions directly derived from the Social Learning Theory contribute to reduce preschoolers' EB. But their multimodal format prevents us to know what causes change in children behavioral adjustment.

\footnotetext{
* Corresponding author.

E-mail addresses: laurie.loop@uclouvain.be (L. Loop), benedicte.mouton@ uclouvain.be (B. Mouton), marie.stievenart@ulg.ac.be (M. Stievenart), isabelle. roskam@uclouvain.be (I. Roskam).
}

\section{Parenting program formats}

Several formats of parenting interventions have been reported that vary according to two dimensions. They vary first according to the number of parenting variables which are manipulated within the program, ranging from a large number to only one, and second according to the nature of these parenting variables, which can be either cognitive or behavioral. Manipulation of parenting cognitions refers to changes in beliefs and thoughts such as causal attributions, cognitive distortions, parental perceptions of their children (Renk, 2011), self-efficacy or emotional states related to parenting such as stress (Kazdin \& Whitley, 2003; Mackler et al., 2015). Manipulation of parenting behavior refers to operant learning theory, in which parents learn how to reinforce children's positive behavior (i.e. by praising) and how to ignore or introduce limit-setting (i.e. time-out) to children's negative behavior (Webster-Stratton, 2004). Parents are therefore helped to model more effective behavior in their child (Furlong et al., 2010). Alongside these two dimensions, i.e. number and nature of parenting variables manipulated, parenting programs range from 
the multimodal format, where a large number of cognitive and behavioral parenting variables are manipulated together, to the specific format, where a single cognitive or behavioral parenting variable is targeted.

The vast majority of evidence-based parenting programs are multimodal. They are typically delivered in a group format and can be viewed as the "standard of care" for child EB (Eyberg, Nelson, \& Boggs, 2008; Nock, 2003). They are based on the conception that EB is associated with multiple parental risk and protective factors, requiring the manipulation of several cognitive and behavioral parenting variables to achieve efficacy (Sandler, Schoenfelder, Wolchik, \& MacKinnon, 2011). This background is shared by standardized and widely implemented parenting programs across the world in diverse cultural contexts, such as Incredible Years (Webster-Stratton \& Herman, 2010), Parent Child Interaction Therapy (Eyberg et al., 2008), and Triple P- Positive Parenting Program (Sanders, 1999). Multimodal parenting programs' efficacy has been evaluated along a continuum measured by effect size (ES) rather than by distinct categories (effective or ineffective) (Menting, de Castro, \& Matthys, 2013). Results of several metaanalyses and systematic reviews have reported small to moderate average effects of multimodal parenting programs in reducing child EB $(d=0.35-0.53)$ (Furlong et al., 2010; Lundahl, Risser, \& Lovejoy, 2006; Piquero, Farrington, Welsh, Tremblay, \& Jennings, 2009). Some meta-analytic reviews have looked exclusively at one specific program, such as Incredible Years, implemented in 50 studies (Menting et al., 2013), or Triple P, implemented in 55 studies (Nowak \& Heinrichs, 2008), with the same finding of small to moderate effects $(d=0.27-0.35)$. Even for those parents who fully complete the programs, $30-50 \%$ of their children continue to show clinical levels of EB (Ollendick \& King, 2012; Webster-Stratton \& Reid, 2010).

What is actually at stake in multimodal parenting interventions was examined in a recent meta-analysis (Mouton, Loop, Stievenart, \& Roskam, 2017). The multimodal format in fact makes it impossible to disentangle the specific effect of each of the parenting variables involved in children's behavioral issues (Ma, Champion, \& Eisenberg, 2004). This problem prevents us from determining which component among the cognitive and behavioral variables is responsible for the greater change in children's EB. In response to this, another specific parenting intervention format has recently been proposed, in which the number of parenting variables manipulated is limited and the nature of these variables is clearly identified (Howe, Beach, \& Brody, 2010; Leijten et al., 2015). Specific parenting interventions have been presented by the authors as micro-trials. These are defined by Howe et al. (2010) as "randomized experiments testing the effects of relatively brief and focused environmental manipulations designed to suppress specific risk mechanisms or enhance specific protective mechanisms, but not to bring about full treatment or prevention effects in distal outcomes". Such a focused manipulation offers the opportunity to isolate a variable and disentangle its impact from that of covariates. In this way, micro-trials help to distinguish between the less and more efficacious elements of parenting interventions, to ascertain for whom and in what conditions these elements are the most efficacious and to explore the potentialities of tailoring interventions to families' needs (Leijten et al., 2015). From this point of view, they appear to be a promising method of discovering the optimal number and the ideal nature of parenting variables to be addressed by interventions.

Recent micro-trials have targeted cognitive (Mouton \& Roskam, 2015; Roskam, 2015) or behavioral parenting variables (Brassart \& Schelstraete, 2015b; Loop \& Roskam, 2016) in a specific onevariable format. The efficacy of specific parenting interventions has also been tested among parents of clinically referred children
(Brassart \& Schelstraete, 2015a). A cognitive micro-trial demonstrated a positive impact of the manipulation of parental selfefficacy beliefs (8-week intervention) on children's EB with a moderate to high effect size $(d=0.61$ at post-test and $d=1.15$ at follow-up) (Roskam et al., 2016). The behavioral micro-trials of Brassart and Schelstraete (2015a) highlighted the efficacy of the manipulation of parental verbal responsiveness (8-week intervention) on children's $E B$, with a moderate effect size $(d=0.58$ at post-test and $d=0.65$ at follow-up).

In sum, effect sizes reported for multimodal and specific parenting interventions suggest slightly higher efficacy for the micro-trial format compared to the multimodal one. This may be due to different duration because multimodal are mainly longer than specific parenting interventions. And programs with longer duration result in smaller effect (Bakermans-Kranenburg, Van Ijzendoorn, \& Juffer, 2008). Beside duration, it may also raise the question of the number and nature of parenting variables to be tackled by programs. With regard to the number of variables, increasing this number could lead to additional gains, and better behavioral adaptation in children. This assumption is in line with the concept of equifinality (Cicchetti \& Rogosch, 1996; Von Bertalanffy, 1968), which considers child behavioral problems as heterogeneous and multiply determined. With regard to this approach, no single mechanism would be sufficient to explain intervention effects on EB reduction (Burke \& Loeber, 2015). However, a recent study (Roskam, Brassart, Loop, Mouton, \& Schelstraete, 2016) demonstrated that stimulating one parenting variable could have not only a specific effect on this target variable, but also a widespread effect on other parenting variables thanks to positive cascading effects. This would be consistent with the model claiming that because parents' psychological states are composed of interacting cognitive and behavioral elements, any treatment which effectively targets one of these systems may lead to a change in all of them (Borkovec, Newman, Pincus, \& Lytle, 2002). Identifying parenting variables that have the power to trigger positive cascading effects in parent-child interaction is therefore important. It also leads to a consideration of the nature of the parenting variables as well as their number. Few studies have actually addressed the extent to which the nature of the manipulated parenting variables influences children's EB. One previous study provided direct comparisons between two one-variable interventions that differed in the nature of the manipulated parenting variable (cognitive or behavioral) (Roskam, Brassart, Loop, Mouton, \& Schelstraete, 2015). Similar efficacy was reported for the two specific interventions, suggesting that variations in the nature of the variable manipulated could be insufficient to cause variations in EB reduction. The contribution of the current study is therefore its comparison of two parenting interventions that varied according to both the number and the nature of the variables involved. The first manipulated one cognitive parenting variable, i.e. self-efficacy beliefs, and the second manipulated two parenting variables, one cognitive and the other behavioral, i.e. self-efficacy beliefs and emotion coaching practices. In this way, the current study contributes to the need for comparisons between parenting interventions that vary according to the number and/or the nature of parenting variables manipulated in order to provide evidence of which parenting program format improves child behavior more effectively.

\section{Parental self-efficacy beliefs and children's behavioral outcomes}

Parental self-efficacy beliefs (SEBs) are defined as parents' selfperceived competence in their role, covering the beliefs, thoughts, values and expectations which are activated in those responsible for raising children (Coleman \& Karraker, 2003). SEBs 
impact directly and indirectly on children's behavior. The indirect effect is due to the strong associations between SEBs and parenting behaviors. High SEBs have been linked to high parental support and low negative control (Jones \& Prinz, 2005; Leerkes \& Crockenberg, 2002; Meunier, Roskam, \& Browne, 2011). Parenting behaviors have been identified as a mediator between SEBs and children's behavioral development. Research has suggested that high SEBs can be a critical buffer against adversity, enabling parents to cope effectively even with "difficult" children (Meunier et al., 2011; Mouton \& Roskam, 2015; Sofronoff \& Farbotko, 2002). High levels of SEBs have been found to predict supportive behaviors in parents, which in turn improve children's adjustment. Conversely, low levels of SEBs tend to promote EB by increasing the use of controlling behavior, criticism, negative teasing and physical punishment (Brody, Flor, \& Gibson, 1999; Gershoff, Lansford, Sexton, Davis-Kean, \& Sameroff, 2012; Gershoff et al., 2010; Shumow \& Lomax, 2002; Zimmer-Gembeck \& Thomas, 2010). SEBs have also been directly related to better adjustment in children of all ages (Ardelt \& Eccles, 2001; Coleman \& Karraker, 2003; Jones \& Prinz, 2005). Several concurrent and longitudinal associations between high SEBs and children's behavioral adjustment, or conversely between low self-efficacy beliefs and EB, have been demonstrated (Jones \& Prinz, 2005; Junttila, Vauras, \& Laakkonen, 2007; Oelofsen \& Richardson, 2006). Highly confident parents are likely to enjoy the interaction with their child, are reaffirmed in their relationship and seek to spend frequent quality time together.

Parental SEBs are manipulated in several multimodal parenting programs, such as Incredible Years (Webster-Stratton \& Hancock, 1998) or Triple-P in level 5 (Sanders, 1999), and identified as an important variable to target in order to reduce children's EB (Deković et al., 2010; Dunsmore, Booker, \& Ollendick, 2013; Morris et al., 2011; Sofronoff \& Farbotko, 2002). However, in these multimodal programs, parental self-efficacy has been inserted as an additional component, not being considered as the core therapeutic and change process. In addition, it has generally been regarded as a positive side-effect indirectly obtained. For example the use of time-out can provide positive vicarious experience to participating parents whose self-efficacy is improved. Parental self-efficacy has also been described as a moderator or a predictor of change (Deković, Asscher, Manders, Prins, \& van der Laan, 2012; Graziano, Reavis, Keane, \& Calkins, 2007; Rothbart \& Bates, 2006). To our knowledge, only one parenting program (Roskam et al., 2016) has specifically targeted this cognitive variable as a way of tackling children's EB. In this focused program, parental self-efficacy improvement has been directly obtained through activities like focusing attention on current positive experience with their child, collecting them in a piggy bank during the week. Contrarily to multimodal interventions, no direct guidance was provided by program deliverers to improve actual parenting behaviors.

\section{Parental emotion coaching practices and children's behavioral outcomes}

Parents' emotion coaching practices (ECPs) are relate to their "meta-emotion philosophy" (Gottman, Katz, \& Hooven, 1996). Every parent holds a unique meta-emotion philosophy which determines their automatic responses to emotions. These responses are translated into parenting practices in relation to their children's emotions, called emotion socialization practices, which convey messages about how to express, understand and regulate these emotional states (Havighurst, Wilson, Harley, \& Prior, 2009). Emotion socialization practices can be divided into "emotion dismissing" and "emotion coaching" conceptualized "as verbalizations and behaviors toward the child rather than as philosophies" (Lunkenheimer, Shields, \& Cortina, 2007). "Emotion dismissing" refers to parents who tend to ignore their own emotions or belittle their importance, do not constructively attend to their children's feelings, and consider that they have to make negative emotions go away. "Emotion coaching" refers to parents being attentive to their children's feelings, discussing goals and practices for managing emotions and viewing children's emotions as an opportunity to teach them to cope with those emotions (Meyer, Raikes, Virmani, Waters, \& Thompson, 2014). The intention to resort to practices that help children regulate, understand and express their emotions is an essential component of the "emotion coaching" parenting style (Grolnick, Kurowski, McMenamy, Rivkin, \& Bridges, 1998; Stansbury \& Sigman, 2000; Zimmermann \& Stansbury, 2003). The role played by parents' ECPs in children's behavioral outcomes is well established (Duncombe, Havighurst, Holland, \& Frankling, 2012). Research highlights the indirect effect of parents' ECPs on children's outcomes longitudinally through their direct effects on children's emotion regulation (Cunningham, Kliewer, \& Garner, 2009). Strong ECPs in parents therefore contribute to the development of children's own emotional competences. Children demonstrate greater awareness, acceptance of emotions, ability to calm themselves and emotion regulation skills (Denham, 1997; Gottman et al., 1996; Lunkenheimer et al., 2007; Ramsden \& Hubbard, 2002; Saarni, 1993; Zeman \& Shipman, 1998). In turn, encouraging these adaptive behaviors (Valiente et al., 2004) helps children fit in social expectations (Cole, Michel, \& Teti, 1994; Saarni, 1993) and tends to reduce EB (Blandon, Calkins, Keane, \& Brien, 2010). Mothers of children displaying EB demonstrate fewer ECPs than mothers of normally developing child (Dunsmore et al., 2013; Katz \& Windecker-Nelson, 2004). Because of their intense, frequent and rapid changes in emotional arousal experiences, children with EB place higher demands of co-regulation on parents and may make it difficult to immediately engage in ECPs (Dunsmore, Booker, Ollendick, \& Greene, 2016). Maternal ECPs may be an important protective factor for children at risk of higher levels of EB, and even more so for children with high emotional lability. ECPs also buffer children against problems of emotion regulation and aggression in the context of high inter-parental conflict (Katz \& Gottman, 1997). Parenting practices specifically related to emotion management coaching are crucial in fostering children's socioemotional and behavioral adjustment (Morris et al., 2011; Shipman et al., 2007).

ECPs have especially been manipulated in the "Tuning in to Kids" (TIK) program (Havighurst, Wilson, Harley, Prior, \& Kehoe, 2010). In particular, TIK manipulates parents' meta-emotion philosophy by stimulating their thoughts, feelings and behaviors in response to their own and their children's emotions. In this way, TIK can be considered as a focused intervention since it targets parents' ECPs. However, both the cognitive and the behavioral sides of ECPs are tackled by the program. To our knowledge, no previous intervention was based on a specific side, be it cognitive or behavioral. Manipulation of the cognitive side is for example achieved through activities like inviting participating parents to consider the extent to which emotions are important in their child development. Manipulation of the behavioral side may be achieved through activities like exposing participating parents to short videos showing positive emotion regulation practices such as verbal or physical comfort (Loop \& Roskam, 2016).

\section{The current study}

The present study compares the efficacy of two parenting interventions sharing the same experimental design but varying in the number and nature of variables targeted for reducing preschoolers' EB. The first was a one-variable intervention manipulating self-efficacy beliefs (cognitive variable). The second was a two-variable intervention manipulating both cognitive (self- 
efficacy beliefs) and behavioral (emotion coaching practices) parenting variables. To the best of our knowledge, this is a first attempt to compare these two parenting program formats directly. The main research question was therefore exploratory in nature.

\section{Method}

\subsection{Participants}

The participants were 94 preschoolers ( $58.5 \%$ boys) and their parents ( $72.3 \%$ mothers). The average age of the children was 52.88 months $(S D=8.32)$, and that of the parents was 36.6 years $(S D=4.70)$. The participants were native French-speakers, and all of the children attended normal schools in the French-speaking part of Belgium.

The first inclusion criterion was that the children must score in the clinical or borderline range of the EB scale (cut-off $=21$ or higher) of the Child Behavior Checklist preschool form (Achenbach \& Rescorla, 2000a). At baseline, the children scored 27.89 on average $(S D=5.15)$. The second criterion was children's age (three to six years old and still in kindergarten at the beginning of the intervention). A brief evaluation of IQ was carried out using two subtests of the WPPSI-III (Wechsler, 2004): the block design subtest (for reasoning IQ) and the information subtest (for verbal IQ). These subtests have been found to correlate highly with the full-scale IQ (Anastasi \& Urbina, 1997). The standardized IQ score obtained with usual WPPSI-III norms was $10.69(S D=2.4)$ on average. In order to select children whose EB was the core mental health problem, children with intellectual disabilities (average IQ < 5.5) and highly gifted children (average IQ > 14.5) were excluded from the study.

As regards the mothers' educational level, $18.1 \%$ had completed secondary school, 26.6\% had gained a first degree and $55.3 \%$ had been educated to master's level or higher. Among the fathers, $17 \%$ had completed secondary school, 30.9\% had gained a first degree and $52.1 \%$ had been educated to master's level or higher. Monthly incomes (total monthly household income including benefits) were less than $€ 2000$ for $32.4 \%$ of the families and higher than $€ 2000$ for $67.1 \%$. Ninety-three percent of the children lived in a two-parent household, 5.3\% had parents who were divorced and $1.1 \%$ were living with a single mother.

\subsection{Data collection procedure}

Data were collected as part of the longitudinal "Hard- $t(w) o-$ Manage (H2M) Children" research program conducted at the Psychological Sciences Research Institute of the Université catholique de Louvain (UCL). The wait list cross-over design was approved by the Ethical Committee of the UCL. The trial has been registered on https://clinicaltrials.gov/, trial number NCT03004781. The parents were informed about the study through pediatricians, schools and social networks. They were invited to take part in a parenting intervention study for children displaying hard-to-manage behaviors such as agitation, non-compliance, impulsivity, aggressiveness, or opposition. Parents who were willing to take part in the intervention were invited to complete an online questionnaire in which socio-demographic information and an assessment of their child's EB was collected. Baseline, post-test and 16-week follow-up (after post-test) data were collected at the university by extensively trained researchers. Parents were told they would be taking part in a longitudinal study, and informed consent was obtained. Using a multi-method approach, data was collected through questionnaires and observations. Parents completed questionnaires assessing children's EB and temperament, parents' temperament and SEBs and the family's score on the CHAOS scale. Parent-child interactions were assessed with the 25-min standardized Crowell procedure
(Crowell \& Feldman, 1988) in order to rate parents' ECPs and child behaviors such as positive affect or irritability. After each visit to the university, parent and child received small rewards (i.e. museum tickets, toys or shopping vouchers provided by sponsors).

During the three-month recruitment period, a total of 64 parents completed the online questionnaire. Nine of them were excluded because their child's EB was not in the clinical range, or was younger than three or older than six, or displayed a developmental condition or did not speak French. Participants who were excluded were directed towards the regular mental health services. Six participants dropped out, citing reasons such as time constraints or a preference for an individual session for their child. A total of 49 participants were assigned at the same time point to the wait list group for eight weeks. Four of them dropped out before the beginning of the program. After eight weeks, the remaining 45 parents were assigned at the same time point either to the SEBs program $(\mathrm{N}=23)$ or to the ECPs + SEBS $(\mathrm{N}=22)$ eight-week program. Assignment was based on a block randomization procedure to ensure that equal numbers were allocated to the two programs. We randomized four parents at a time. Blocks of four parents were formed by considering the names of the parents in alphabetical order. Block size of four resulted in six different possible ways to randomize four parents equally to the two programs. We asked the computer to randomly select one of the six types of block. When the first parent was randomized, it determined the program for the four parents within the block. The randomization procedure was performed with ten blocks. The size of the last block was of five. However, since group sessions have been organized after work hours several days in a week, some flexibility was given to the participants with regard to timetable. It was made to maximize convenience for participants and to limit drop-out. Therefore, 19 parents finally participated to the first group (SEBs) and 26 to the second one (ECPs + SEBs) resulting in slight imbalance. A pre-post wait list control group design was chosen for ethical reasons. Although such a design prevents comparison at follow-up, it offers an alternative to families who would be left without any support otherwise. For these reasons, it is a commonly used design in parenting intervention (Sanders, MarkieDadds, Tully, \& Bor, 2000). The flow of participants and the dropout rate at each stage of the micro-trials is shown in Fig. 1.

\subsection{Programs}

Except for the programs' content, exactly the same procedure was followed in the two eight-week programs. They consisted of eight 1.5 -h weekly group sessions with 7-15 parents, including both mothers and fathers (the latter averaging 30\% in each group). The content was specific to the parenting variable manipulated, but the basic program techniques were the same, i.e. brainstorming, video or audio clips, role-plays, personalized video-feedback on parent-child interactions and homework. Between each session, a brief phone call was made, purely to answer the parents' questions about the homework and to encourage its completion. The sessions were led by two extensively trained PhD students on the basis of a program delivery manual. This was created to standardize each session with regard to instructions to participants, timetable and activities (description and materials). The manual also included recommendations on the session leaders' general attitudes, which had to be neutral, open and characterized by unconditional acceptance towards the parents. This standardization included information about how to lead a group so as to remain exclusively focused on the manipulated parenting variable. For example, in the SEBs program, typical responses were provided in the manual to parents' questions about parenting practices which were not under consideration in this one-variable intervention. The manual also 


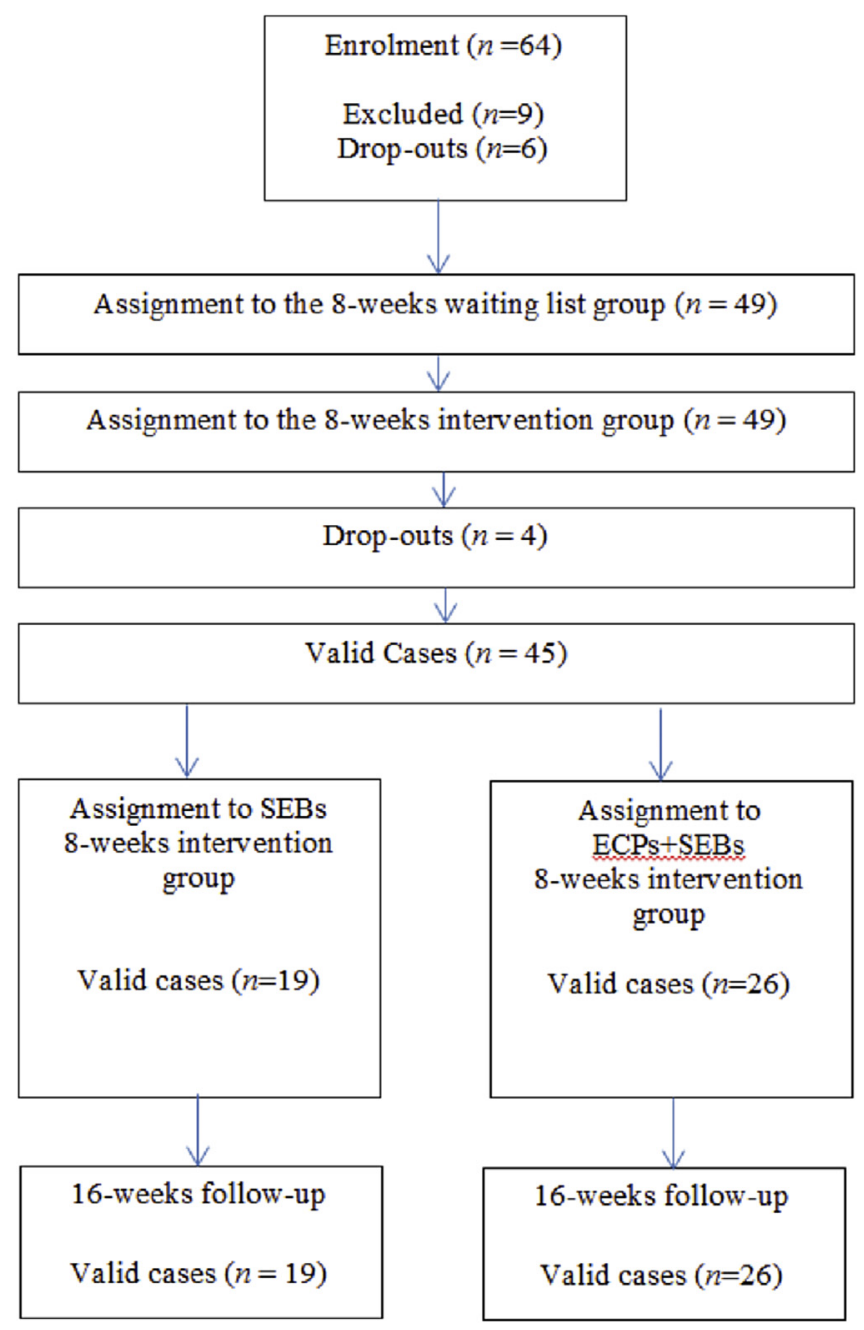

Fig. 1. Flow of participants through each stage of the study.

contained explanation on how the program had to be presented to participants. They were informed of the experimental nature of the intervention resulting in a focus on specific aspects of parenting. Participants were invited to trust the program deliverers about the topics selected in the program content. For example in the SEBs intervention, parents were informed that parenting practices would not be addressed during the group sessions. They received no direct instructions from the deliverers on the way parents should deal with children's problem behaviors. The intervention aimed at empowering parents by making them realize how much they know about their child, by uplifting their negative perceptions often leading to guilt and by reopening their parenting possibilities. In the ECPs + SEBs program, only the behavioral components of ECPS were trained by delivering concrete practices - improving children's emotion regulation to parents. No specific activities focused on cognitive representations of emotions. Fifty-six percent of parents attended all eight sessions and $100 \%$ of parents attended at least 7 sessions across the two programs. If sessions were missed, parents received information about the homework during the phone call and were invited to come 15 min early to the next session in order to catch up.

The eight-week SEBs intervention was the Confident Parents Intervention (Roskam et al., 2016). This program focuses on the stimulation of the cognitive parenting variable of SEBs. The content of the intervention is based on Bandura's Social Learning Theory
(Bandura, 1977), which posits that SEBs should be considered not as a personality trait but rather as a context-dependent concept (Bandura, 1977, 1982). They can be manipulated, as has been demonstrated in social psychology, sport studies (Coffee \& Rees, 2011) and brief micro-trials (Mouton \& Roskam, 2015). Social Learning Theory holds that SEBs are rooted in individual factors (e.g. personal history of accomplishment, emotional arousal and its physiological impact) as well as in contextual factors (e.g. verbal feedback from others, social comparisons) (Bandura, 1989). Accomplishments are the strongest source of SEBs, followed by vicarious experience (an evaluation process based on seeing others with widely differing characteristics perform), verbal persuasion and emotional arousal (Bandura, 1977). In parenting, SEBs are therefore expected to depend on parents' past and actual experience with their children (successes and failures) and on the emotional arousal this experience may induce. Feedback from others (in particular comments from relatives, teachers, doctors, friends or a significant other for the parent) and social comparison with other parents are also major contributors to self-efficacy. The content of the program was as follows: What kind of parent am I? (session 1); Having a positive representation of my child (session 2 ); Being comfortable with praise (session 3); To what extent does my child make me feel competent or not? (session 4); Talking to others about my child to receive feedback about me as a parent (session 5); Thinking about me and my child (session 6); Selfevaluation through video feedback based on baseline observation of the participants (sessions 7 and 8). All activities were chosen to directly target the four sources of SEBs. For example, to improve negative emotional arousal, parents have been trained to identify their own automatic cognitions when their child displays externalizing behaviors. The therapeutic aim was to raise parents' awareness of these automatic processes and increase their anticipation capacities to limit the activation of such processes (Gavița, Joyce, \& David, 2011). Moreover in order to reinforce their SEBs, parents were requested to ask to a significant other (their own parents, siblings, best friends, etc.) to give them a positive feedback on their parenting. Effects of these feedbacks have been discussed within the group. For a more detailed presentation of the program content, see (Roskam et al., 2016).

The eight-week ECPs + SEBs intervention focused on stimulating two parenting variables: one cognitive (SEBs) and one behavioral (ECPs). Sessions were divided into two blocks: the first four weeks focused on ECPs and the last four weeks focused on SEBs. This subdivision was chosen in order to devote the same time to each of the two variables while remaining focused on one specific target in each session. The sessions targeting ECPs were based on the concept of parental meta-emotion philosophy (Gottman et al., 1996) and its two parenting styles (emotion coaching and emotion dismissing). In order to focus exclusively on the behavioral component of ECPs, we stimulated parents' behaviors in response to their children's emotions, but not parents' feelings and thoughts about emotions, which correspond to the cognitive component of the concept of meta-emotion philosophy. Such a focus on the behavioral component of ECPs has been previously used (Ellis, Alisic, Reiss, Dishion, \& Fisher, 2014a; Lunkenheimer et al., 2007). It is in line with recent recommendations to evaluate parents' emotion coaching beliefs and behaviors separately (Castro, Halberstadt, Lozada, \& Craig, 2015; Halberstadt et al., 2013). As demonstrated in a brief micro-trial study (Loop \& Roskam, 2016) and parenting intervention studies (Havighurst et al., 2009, 2010, 2013), the behavioral components of ECPs are susceptible to change in response to direct intervention. These behavioral components of ECPs impact children's behavior through three social learning mechanisms: a) parents' expression and regulation of their own emotions b) parents' reactions to children's expression of 
emotion and c) parents' coaching and discussion of children's emotions (Eyberg et al., 2008; Halberstadt, 1991).

Sessions stimulating SEBs were based on exactly the same theoretical background as those used in the one-variable SEBs intervention, but implemented in a shorter version in order to remain in the 8-week format. The content of the ECPs + SEBs program is as follows: When my child is unbearable: Understanding my emotional reactions (session 1); Recognizing my child's emotions (session 2); How to speak about emotions with my child (session 3); How to regulate my child's emotions: emotion regulation practices (session 4); Being comfortable with praise (session 5); Thinking positively about my child (session 6); Self-evaluation through video feedback based on baseline observation of the participants (sessions 7 and 8). All activities were chosen to directly target the behavioral component of ECPs (4 first weeks) and the four sources of SEBs (4 last weeks). For example, in session 4, parents were exposed to short videos showing parent-child interaction where the parent used explicit ECPs. This was made to expand participants' directory of practices. Parents were also invited to experiment these ECPs through role playing.

\subsection{Measures}

A multi-method assessment consisting of parent-reported and observed measures was used at each stage of the study (baseline, post-test and follow-up). Three different kinds of measures were also used to respond to various goals. Control measures, only evaluated in baseline, served to confirm the equivalence between the three groups (wait list, SEBs program and ECPs + SEBs program). Manipulation check measures were used to gauge the improvement in the parenting variables specifically manipulated (SEBs and/or ECPs) after the eight-week intervention. Outcome measures allowed us to test the extent to which the two interventions impacted children's EB and observed behavior.

\subsection{Control measures}

Child temperament was measured with the Colorado Childhood Temperament Inventory (CCTI) (Rowe \& Plomin, 1977), a 25-item questionnaire designed for one-to six-year-old children and encompassing five scales: Sociability, Emotionality, Activity, Attention Span Persistence and Soothability. All items were rated by parents with Likert-type scales ranging from 1 ("not at all like my child") to 5 ("a lot like my child"). Examples of items are "My child is always on the go" for the activity scale or "When upset by an unexpected situation, my child quickly calms down" for the soothability scale. Internal consistency was reported to be good, with Cronbach's alphas ranging from 0.73 to 0.88 and test-retest reliabilities of $r=0.43$ to 0.80 .

Parent temperament was measured on the dimensions of Emotionality, Activity, and Sociability (EAS: Buss \& Plomin, 1984) using 20 Likert five-point items. Emotionality was further divided into three subscales: Fear, Anger, and Distress. Examples of items are "I prefer working with others rather than alone" for the sociability scale, or "I'm easily frightened" for the fear scale. The internal consistency of the five scales (Fear, Anger, Distress, Activity, and Sociability) in the French validated version ranged from 0.62 to 0.80 (Rouxel, Briec, Juhel, \& Le Maner-Idrissi, 2013).

Family chaos was measured with the Confusion, Hubbub, and Order Scale (CHAOS) (Matheny, Wachs, Ludwig, \& Philips, 1995). This 15-item parent-reported questionnaire evaluates "environmental confusion and disorganization", i.e. high levels of noise, crowding and people coming and going in children's home environment. Examples of items are: "We can usually find things when we need them" or "The atmosphere in our home is calm". Based on current practice, a single score is derived from the CHAOS questionnaire to represent the parent's report of home characteristics. This single score is created by obtaining a simple sum of responses for the 15 items. The true or false responses are scored so that a higher score represents more chaotic, disorganized and hurried characteristics of the home. Cronbach's alpha for the $15 \mathrm{CHAOS}$ items was 0.79 . The test-retest stability correlation for the total CHAOS score was 0.74 . CHAOS has also been reported to be correlated to parents' educational level and socio-economic status (Matheny et al., 1995).

\subsection{Manipulation check measures}

Parental self-efficacy beliefs (SEBs) were assessed with the Global Parental Self-Efficacy Scale of Meunier and Roskam (2009). Based on Bandura's Social Learning Theory (1977) and on subsequent parenting research (Coleman \& Karraker, 1998), this is a 25-item scale related to five domain-specific SEBs factors: Discipline, Nurturance, Playing, Instrumental Care, and Teaching. Items are in the form of affirmatives, for example: "I am able to sense when my child is starting to become distressed" for the Nurturance subscale. The measure has been validated on 705 French-speaking parents and displays good psychometric properties, according to Meunier and Roskam (five-factor solution explaining $53.1 \%$ of the variance, $\alpha$ ranging from 0.60 to $0.84,2009$ ). In order to limit the number of predictors in the analyses, a main SEBs score was computed $(\alpha=0.76)$. Moderate to high correlations were observed between four of the five domain-specific measures ( $r=0.28$ to 0.47 ), suggesting a higher-order domain-general parental SEBs measure. The instrumental care scale was excluded from the analyses because of its limited correlation with other scales. The procedure used in the current study is in line with Bandura's formulation (1977), which suggested that the most valid approach for determining domainlevel SEBs regarding a multidimensional construct such as parenting is achieved by combining the efficacy information conveyed by several behaviorally specific assessments.

Parental emotion coaching practices (ECPS) were observed using the emotional responsiveness parental scale in the Crowell Procedure (MCIT, Crowell \& Feldman, 1988). Caregivers' emotional responsiveness has been described as consistent with the concept of parents' ECPs (Cassidy, 1994; Havighurst et al., 2009). The scale measuring parents' emotional responsiveness reflects the caregiver's level of emotional support and responsiveness in connection with task completion. It takes account of how parents create and implement practices to maintain a positive emotional context in interactions with their child, how they demonstrate interest and enthusiasm regarding the child's emotions towards task completion, how they reflect and empathize with the child's emotions and how they regulate their own emotions. These different practices are all relevant to ECPs. Widely used (Coleman \& Karraker, 2003; Crowell \& Feldman, 1988, 1989; Crowell, O'Connor, Wollmers, Sprafkin, \& Rao, 1991) and recently validated with Frenchspeaking preschoolers (Loop, Mouton, Brassart, \& Roskam, 2016), this measure is unstructured enough to allow for "real-life" or spontaneous interactions. In this study, in order to arouse children's emotions and therefore elicit parents' ECPs, the parent-child interaction observation consisted of two main episodes: a free play session (10 min) and a frustration tasks session (15 min). The frustration tasks session consisted of the "tidying toys away" task followed by two increasingly difficult problem-solving tasks (puzzles in 3D). Due to the common nature of these three frustration tasks, a global frustration task score was calculated, corresponding to the sum of the parent's emotional responsiveness in each frustration task. The parent's emotional responsiveness was coded on a seven-point Likert scale in each task and examined in two time 
sequences; free play (ranging from 1 to 7 ) and frustration tasks (sum of the scale on each task ranging from 3 to 21). These time sequences were different in nature, with the first involving a very common play situation giving rise to children's positive emotions, and the second involving a difficult situation designed to generate children's negative emotions. Coding was done by two independent trained coders, one of whom was certified by the University of Tulane (USA), with a mean intercoder reliability of 0.92 calculated with the weighted Kappa coefficient on $25 \%$ of the sample. Coders were blind with respect to the participants' allocated condition and the study phase (baseline, post-test and follow-up).

\subsection{Outcome measures}

Child externalizing behavior was reported by parents using the 32-item preschool version of the Child Behavior Check-List or CBCL (Achenbach \& Edelbrock, 1981). The CBCL consists of three-point Likert scales: not at all, moderately, or often present. For the current study, data collection was limited to two first-order scales, "attention problems" and "aggressive behavior", enabling us to calculate an externalizing behavior total score building the secondorder "externalizing behavior (EB)" scale. The psychometric properties of the initial version of the scale were good, with $\alpha$ of 0.89 for "attention problems" and 0.96 for "aggressive behavior", and $r=0.58$ and 0.62 for test-retest reliability (Achenbach \& Rescorla, $2000 b)$. For the French version, the psychometric properties obtained by the authors of the current study from an independent sample of 186 preschoolers were good and comparable with those obtained in the original American version of the scale, with $\alpha$ of 0.79 for "attention problems" and 0.93 for "aggressive behavior", and $r=0.50$ and 0.56 for test-retest reliability computed in a subsample of participants (15\%). In the second-order EB scale, the cut-off to discriminate clinical and borderline levels of EB from non-clinical children was placed at 21.

Child observed behavior was assessed using six Crowell child scales (Crowell \& Feldman, 1988) scored on a seven-point Likert scale. Positive affect (smiling and laughing), withdrawal/indifference (disinterest in the relationship due to sadness or depression), irritability (fighting, withdrawn behavior with anger, sulking), noncompliance (not listening to the parent's suggestions or requests) and aggression (verbal or physical) towards the parent, as well as persistence and enthusiasm towards the task were coded. The scale of withdrawal/indifference, present in the original procedure, was eliminated due to its low variance. Based on the French validation of the Crowell Procedure (Loop et al., 2016), a global child observed behavior score was computed by adding the scores of each scale (positive affect, enthusiasm, persistence and the inverse of the scores for irritability, non-compliance and aggression). This global score was calculated for the two time sequences: free play (ranging from 6 to 42) and frustration tasks (sum of the scales on each tasks ranging from 18 to 126). Coding was done by two independent coders, trained by one coder certified by the University of Tulane (USA), with a mean intercoder reliability of 0.92 calculated with the weighted Kappa coefficient on $25 \%$ of the sample.

\subsection{Data analysis}

A first preliminary analysis consisted in checking the comparability between the participants assigned to the two intervention groups (SEBs and ECPs + SEBs). The two groups were compared with ANOVAs and $\mathrm{X}^{2}$ according to socio-demographic data, baseline level of child's EB and IQ. The two groups were also compared in terms of control measures (family chaos, child and parent temperament). Temperament was used as control measure with regard to differential susceptibility hypothesis (Belsky \& Pluess,
2009) suggesting that intervention effect may be due to differences in participant or child temperament. Preliminary analyses were also conducted to verify the baseline level of parents' SEBs and ECPs as well as the level of child EB and observed behavior in the two groups. As a final preliminary analysis, correlations between the outcome variables, i.e. child EB and observed behavior in free play and frustration tasks, were computed. As a way of checking the manipulations, we verified that the two interventions were effective in changing the targeted parenting variables (SEBs and ECPs) by computing an ANOVA 2 times (baseline, eight weeks later) $\mathrm{x} 3$ groups (wait list, SEBs and ECPs + SEBs interventions), with SEBs and ECPs as dependent variables. Time $\times$ group interaction effects were analyzed for SEBs and ECPs. SEBs were expected to improve in the two interventions but not in the wait list. A different interaction effect was expected for ECPs, which were expected to improve in the ECPs + SEBs, but not in the SEBs intervention or in the wait list group.

The main statistical analysis consisted of comparing the change in child EB and observed behavior according to the intervention format. First, we verified that the two interventions were effective in reducing child EB and enhancing child observed behavior by computing an ANOVA 2 times (baseline vs. eight weeks later) x 3 groups (wait list vs. SEBs intervention vs. ECPs + SEBs intervention), with child EB and observed behavior as dependent variables. A time $\times$ group interaction effect was expected for the two outcomes, which were expected to change in the two interventions but not in the wait list. Second, the extent to which the intervention format influenced the rate of change in child EB and observed behavior over the course of the study was evaluated with repeated-measures ANOVAs, with time (baseline vs. 8 weeks later vs. follow-up) as the three-level within-subjects variable, group (SEBs vs. ECPs + SEBs) as the two-level between-subjects variable, and child EB and observed behavior as the dependent variables. A significant main effect of time was expected, consisting of a decrease in EB and an improvement in observed behavior. Significant time $\times$ group interactions were also tested to study which parenting intervention format, i.e. one-variable vs. two-variable, was the more effective in reducing child EB and improving child observed behavior.

\section{Results}

\subsection{Preliminary analyses}

Descriptive data and statistical comparisons between groups are presented in Tables 1 and 2. No significant differences were found between the three groups regarding control variables (socio-demographic data, family chaos, child and parent temperament), except for the child's temperament trait of activity, which was slightly higher in the SEBs intervention. When we compared groups according to SEBs, ECPs, child EB and observed behavior baseline levels, we found significant differences for parents' ECPs in the frustration task, $F(1,44)=5.49, p<0.05$, and child observed behavior during free play, $F(1,44)=5.06, p<0.05$, and frustration task, $F(1,44)=9.23, p<0.01$. The examination of the plots indicated that two parent-child dyads had particular outlier profiles at baseline. When excluded, the three groups were strictly comparable. It was decided to perform all subsequent analyses both with and without these two outlier dyads. Since no differences in the results were found whether they were considered or not, only the results with the entire sample are presented here.

With regard to the associations between the outcome variables, the correlation between child EB as reported by the parents and child observed behavior as assessed by the researchers ranged from 0.03 to 0.09 , suggesting that the behaviors under consideration in the two assessment methods were different. The correlations 
Table 1

Descriptives and statistics for socio-demographic data in the two groups.

\begin{tabular}{|c|c|c|c|}
\hline & $\begin{array}{l}\text { SEBs } \\
n=19\end{array}$ & $\begin{array}{l}\text { ECPs }+ \text { SEBs } \\
n=26\end{array}$ & Statistics \\
\hline & $M(S D)$ & $M(S D)$ & \\
\hline Parent's age (years) & $37.24(7.05)$ & $36.65(3.94)$ & $F(1,44)=0.12$ \\
\hline Child's age (months) & $53.95(8.61)$ & $53(7.58)$ & $F(1,44)=0.15$ \\
\hline Child's gender (\% boys) & $63.2 \%$ & $57.7 \%$ & $X^{2}(2)=0.88$ \\
\hline Parent's gender (\% mother) & $73.7 \%$ & $69.2 \%$ & $X^{2}(2)=0.91$ \\
\hline \multicolumn{4}{|c|}{ Mother's Educational level (\%) } \\
\hline - Primary and secondary & $26.3 \%$ & $11.5 \%$ & $X^{2}(3)=0.64$ \\
\hline - High school & $15.8 \%$ & $30.8 \%$ & \\
\hline - University and higher & $57.9 \%$ & $57.7 \%$ & \\
\hline \multicolumn{4}{|c|}{ Father's Educational level (\%) } \\
\hline - Primary and secondary & $15.8 \%$ & $15.4 \%$ & $X^{2}(3)=0.58$ \\
\hline - High school & $21.1 \%$ & $42.3 \%$ & \\
\hline - University and higher & $63.2 \%$ & $42.3 \%$ & \\
\hline \multicolumn{4}{|l|}{ Parent's income (\%): } \\
\hline$<2000$ euros & $35.6 \%$ & $29.2 \%$ & $X^{2}(2)=0.66$ \\
\hline$>2000$ euros & $64.4 \%$ & $69.8 \%$ & \\
\hline \multicolumn{4}{|l|}{ Families (\%): } \\
\hline - 2 Parents household & $89.5 \%$ & $100 \%$ & $X^{2}(3)=0.48$ \\
\hline - Divorced parents & $10.5 \%$ & $0 \%$ & \\
\hline - Single mother & $0 \%$ & $0 \%$ & \\
\hline Child's EB & $27.74(4.49)$ & $27.96(5.95)$ & $F(1,44)=0.01$ \\
\hline Child's IQ & $11(2.16)$ & $10.88(2.53)$ & $F(1,44)=0.02$ \\
\hline
\end{tabular}

Note. SEBs = Self-efficacy beliefs; ECPs = Emotion coaching practices;

$\mathrm{EB}=$ Externalizing behavior; IQ = Intelligence quotient.

Table 2

Comparability between intervention groups at baseline.

\begin{tabular}{|c|c|c|c|}
\hline & $\begin{array}{l}\text { SEBs } \\
n=19\end{array}$ & $\begin{array}{l}\text { ECPs }+ \text { SEBs } \\
n=26\end{array}$ & Statistics \\
\hline & $M(S D)$ & $M(S D)$ & \\
\hline Chaos & 5.89 (3.19) & $6.85(3.09)$ & $F(1,44)=1.01$ \\
\hline \multicolumn{4}{|l|}{ Child's temperament: } \\
\hline - Emotionality & $18.53(4.69)$ & $19.5(2.86)$ & $F(1,44)=0.74$ \\
\hline - Activity & $19.58(4.11)$ & $16.58(3.72)$ & $F(1,44)=6.53^{*}$ \\
\hline - Sociability & $16.79(4.63)$ & $16.54(4.62)$ & $F(1,44)=0.03$ \\
\hline - Attention/persistence & $13.95(3.22)$ & $12.69(3.99)$ & $F(1,44)=1.26$ \\
\hline - Soothability & $11.47(4.03)$ & $11.42(2.84)$ & $F(1,44)=0.00$ \\
\hline \multicolumn{4}{|l|}{ Parent's temperament: } \\
\hline - Fear emotionality & $2.35(1.11)$ & $2.23(0.69)$ & $F(1,44)=19$ \\
\hline - Distress emotionality & $2.93(1.03)$ & $2.99(0.82)$ & $F(1,44)=0.04$ \\
\hline - Anger emotionality & $2.98(1.04)$ & $2.88(0.75)$ & $F(1,44)=0.13$ \\
\hline - Activity & $2.92(0.88)$ & $3.33(0.71)$ & $F(1,44)=3.04$ \\
\hline - Sociability & $3.44(0.73)$ & $3.33(0.63)$ & $F(1,44)=0.29$ \\
\hline SEBs & $2.96(0.79)$ & $3.01(0.53)$ & $F(1,44)=0.01$ \\
\hline \multicolumn{4}{|l|}{ ECPs } \\
\hline - Free play & $5(0.94)$ & $4.79(0.83)$ & $F(1,44)=1.49$ \\
\hline - Frustration tasks & $15.05(2.48)$ & $13.75(1.84)$ & $F(1,44)=5.49^{*}$ \\
\hline Child's EB & $27.74(4.49)$ & $27.42(5.83)$ & $F(2,91)=0.08$ \\
\hline \multicolumn{4}{|c|}{ Child's observed behavior: } \\
\hline - Free play & $34.15(3.02)$ & $32.45(2.60)$ & $F(1,44)=5.06^{*}$ \\
\hline - Frustration tasks & $96.84(7.7)$ & $90.04(8.71)$ & $F(1,44)=9.23^{* *}$ \\
\hline
\end{tabular}

${ }^{* *} p<0.01 * p<0.05$

Note. SEBs = Self-efficacy beliefs; ECPs = Emotion coaching practices; $\mathrm{EB}=$ Externalizing behavior.

between child observed behavior during free play and frustration tasks were moderate, $0.46, p<0.01$. Subsequent analyses were therefore performed for each of the three outcome variables separately.

\subsection{Manipulation check}

As presented in Table 3, statistical comparisons between baseline and eight-week measurements of the parenting variables support a manipulation effect. A significant main effect of time was found for parents' SEBs, $F(2,93)=20.83, p<0.001$, and ECPs in frustration tasks, $F(2,93)=7.61, p<0.01$, meaning that these parenting variables improved in the two groups. Two time $\times$ group interactions were found to be significant for parents' SEBs, $F(2,93)=3.59, p<0.05$, and ECPs both during free play, $F(2,93)=12.07, p<0.001$, and frustration tasks, $F(2,93)=20.43, p$ $<0.001$. As expected, parents' SEBs improved in the two interventions but not in the wait list. Parents' ECPs improved in the ECPs + SEBs intervention, but not in the SEBs intervention or in the wait list groups, as expected. Taken together, these results confirmed that the two interventions were effective in changing the targeted parenting variables in the expected direction.

\subsection{Comparison of behavioral change between intervention formats}

Descriptive data and statistical comparisons between baseline, eight-week and follow-up measurements of child behavior variables are presented in Table 4. For comparisons between the three groups, a main effect of time was identified for child EB, $F(2,93)=31.05, p<0.001$, as well as for child observed behavior observed in free play, $F(2,93)=7.45, p<0.01$, and frustration tasks, $F(2,93)=14.94, p<0.001$. These results indicate a decrease of child $\mathrm{EB}$ in the entire sample, even in the wait list. However, time $\times$ group interactions showed a trend, $F(2,93)=2.55, p<0.10$, suggesting that the child EB reduction was higher in the two intervention groups than in the wait list. Significant time $\times$ group interactions were also found for child observed behavior in free play, $F(2,93)=6.97, p<0.01$, and frustration tasks, $F(2,93)=13.2, p$ $<0.001$, indicating a greater improvement in the ECPs + SEBs intervention than in the SEBs intervention and wait list groups. With regard to the comparison between the SEBs and ECPS + SEBs interventions over the three measurement points, a main effect of time was replicated for child EB reduction, $F(2,45)=27.95, p$ $<0.001$, as well as for the improvement of observed behavior in free play, $F(2,45)=9.61, p<0.001$, and frustration tasks, $F(2,45)=26.40$, $p<0.001$. Also, a significant time $\times$ group interaction, $F(2,45)=4.29, p<0.05$ demonstrated a greater reduction of child EB in the SEBs intervention than in the ECPs + SEBs intervention. Other significant time $\times$ group interactions were reported in free play, $F(2,45)=5.77, p<0.05$, and frustration tasks, $F(2,45)=12.53, p$ $<0.001$, indicating a greater improvement in the ECPs + SEBs intervention than in the SEBs intervention. Taken together, these results confirm that both interventions appear effective in improving children's behavior. They also underline that the first (SEBs) has greater improvements in child behavior when reported by the parent and the second (CPSs + SEBs) has greater improvements in child behavior when observed.

\section{Discussion}

The main goal of the current study was to identify which parenting intervention format (one-variable versus two-variable) caused the greatest behavioral adjustment in children. This behavioral adjustment was assessed with a multi-method and a multi-informant method. It was measured on the one hand by parent report and by the observation of the child's behavior by a trained coder on the other hand. The main goal was achieved by comparing two eight-week interventions manipulating parenting variables relating to EB (SEBs versus ECPs + SEBs). The results highlighted that compared to the wait list condition, both intervention formats tended to cause a significant reduction in child EB, but that the two-variable format also caused a significant improvement in observed behavior, i.e. children's behavior observed in the interaction with their parent. The children of 
Table 3

Manipulation check.

\begin{tabular}{|c|c|c|c|c|c|c|c|c|}
\hline & \multicolumn{2}{|l|}{$\begin{array}{l}\text { Wait list } \\
\mathrm{N}=45\end{array}$} & \multicolumn{2}{|l|}{$\begin{array}{l}\text { SEBs } \\
\mathrm{N}=19\end{array}$} & \multicolumn{2}{|l|}{$\begin{array}{l}\mathrm{ECPs}+\mathrm{SEBs} \\
\mathrm{N}=26\end{array}$} & \multirow[t]{2}{*}{$\begin{array}{l}\text { Time effect } \\
F(2,93)\end{array}$} & \multirow[t]{2}{*}{$\begin{array}{l}\text { Time } \mathrm{x} \text { group effect } \\
F(2,93)\end{array}$} \\
\hline & $\begin{array}{l}\text { Baseline } \\
M(S D)\end{array}$ & $\begin{array}{l}8 \text { weeks later } \\
M(S D)\end{array}$ & $\begin{array}{l}\text { Baseline } \\
M(S D)\end{array}$ & $\begin{array}{l}8 \text { weeks later } \\
M(S D)\end{array}$ & $\begin{array}{l}\text { Baseline } \\
M(S D)\end{array}$ & $\begin{array}{l}8 \text { weeks later } \\
M(S D)\end{array}$ & & \\
\hline SEBs & $2.91(0.63)$ & $3(0.63)$ & $2.96(0.79)$ & $3.30(0.50)$ & $2.99(0.52)$ & $3.31(0.45)$ & $20.83^{* * *}$ & $3.59^{*}$ \\
\hline ECPs in free play & $5.08(0.88)$ & $4.76(0.83)$ & $5.06(0.93)$ & $5(0.97)$ & $4.65(0.96)$ & $5.62(0.80)$ & 2.47 & $12.07^{* * *}$ \\
\hline ECPs in Frustration tasks & $14.77(2.55)$ & $13.85(2.28)$ & $15.11(2.54)$ & $15.38(1.81)$ & $13.46(2.06)$ & $16.46(1.9)$ & $7.61^{* *}$ & $20.43^{* * *}$ \\
\hline
\end{tabular}

$\dagger p<0.10^{*} p<0.05^{* *} p<0.011^{* * *} p<0.001$

Note. SEBs = Self-efficacy beliefs; ECPs = Emotion coaching practices.

Table 4

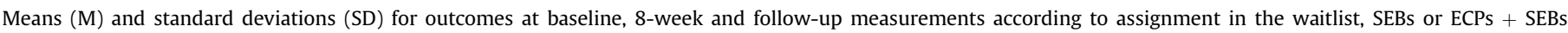
intervention, and ANOVAs results.

\begin{tabular}{|c|c|c|c|c|c|c|c|c|c|c|c|c|}
\hline & \multicolumn{2}{|l|}{ Wait list } & \multicolumn{3}{|l|}{ SEBs } & \multicolumn{3}{|c|}{$\mathrm{ECPs}+\mathrm{SEBs}$} & \multicolumn{2}{|c|}{$\begin{array}{l}\text { ANOVA } 2 \text { (time) } * \\
3 \text { (groups) }\end{array}$} & \multicolumn{2}{|c|}{$\begin{array}{l}\text { ANOVA } 3 \text { (time) } * 2 \\
\text { (groups) }\end{array}$} \\
\hline & $\begin{array}{l}\text { Baseline } \\
M(S D)\end{array}$ & $\begin{array}{l}8 \text { weeks } \\
\text { later } \\
M(S D)\end{array}$ & $\begin{array}{l}\text { Baseline } \\
M(S D)\end{array}$ & $\begin{array}{l}8 \text { weeks } \\
\text { later } \\
M(S D)\end{array}$ & $\begin{array}{l}\text { Follow- } \\
\text { up } \\
M(S D)\end{array}$ & $\begin{array}{l}\text { Baseline } \\
M(S D)\end{array}$ & $\begin{array}{l}8 \text { weeks } \\
\text { later } \\
M(S D)\end{array}$ & $\begin{array}{l}\text { Follow- } \\
\text { up } \\
M(S D)\end{array}$ & $\begin{array}{l}\text { Time } \\
F(2,93)\end{array}$ & $\begin{array}{l}\text { Time } \mathrm{x} \\
\text { group } \\
F(2,93)\end{array}$ & $\begin{array}{l}\text { Time } \\
F(2,45)\end{array}$ & $\begin{array}{l}\text { Time } \mathrm{x} \\
\text { group } \\
F(2,45)\end{array}$ \\
\hline Child's EB & $\begin{array}{l}27.92 \\
(5.04)\end{array}$ & $\begin{array}{l}25.90 \\
(6.00)\end{array}$ & $\begin{array}{l}27.74 \\
(4.49)\end{array}$ & $\begin{array}{l}24.00 \\
(6.81)\end{array}$ & $\begin{array}{l}19.37 \\
(5.39)\end{array}$ & $\begin{array}{l}27.26 \\
(5.95)\end{array}$ & $\begin{array}{l}22.77 \\
(6.02)\end{array}$ & $\begin{array}{l}23.23 \\
(5.34)\end{array}$ & $31.05^{* * *}$ & $2.55 \dagger$ & $27.95^{* * *}$ & $4.29 *$ \\
\hline Child's observed behavior in free play & $\begin{array}{l}33.57 \\
(3.72)\end{array}$ & $\begin{array}{l}33.40 \\
(3.20)\end{array}$ & $\begin{array}{l}34.22 \\
(3.09)\end{array}$ & $34.66(2.8)$ & $\begin{array}{l}34.52 \\
(2.03)\end{array}$ & $\begin{array}{l}32.11 \\
(2.99)\end{array}$ & $35.53(3.5)$ & $\begin{array}{l}36.11 \\
(2.51)\end{array}$ & $7.45^{* *}$ & $6.97^{* *}$ & $9.61^{* * *}$ & $5.77^{*}$ \\
\hline $\begin{array}{l}\text { Child's observed behavior in } \\
\text { frustration tasks }\end{array}$ & $\begin{array}{l}93.38 \\
(12.41)\end{array}$ & $\begin{array}{l}92.81 \\
(10.86)\end{array}$ & $\begin{array}{l}97.55 \\
(7.25)\end{array}$ & $\begin{array}{l}99.44 \\
(9.98)\end{array}$ & $\begin{array}{l}100.42 \\
(8.3)\end{array}$ & $\begin{array}{l}88.57 \\
(9.84)\end{array}$ & $\begin{array}{l}100.65 \\
(7.88)\end{array}$ & $\begin{array}{l}104.00 \\
(7.55)\end{array}$ & $14.94^{* * *}$ & $13.20^{* * *}$ & $26.40^{* * *}$ & $12.53^{* * *}$ \\
\hline
\end{tabular}

$\dagger p<0.10^{*} p<0.05^{* *} p<0.01^{* * *} p<0.001$.

parents whose SEBs and ECPs were stimulated displayed more positive affect, enthusiasm and persistence and lower irritability, non-compliance and aggression. These results are in agreement with those of Webster-Stratton (Webster-Stratton \& Taylor, 2001), who identified the joint manipulation of cognitive and behavioral parenting variables as a key factor of program efficacy. However, when across the three measurement points, the one-variable format led to a greater decrease in child EB as reported by the parents at follow-up than the two-variable format. The contrary was reported for child observed behavior, which improved to a greater extent in the SEBs + ECPs intervention than in the SEBs one.

How can we explain these results? Thanks to the randomized controlled trial design of the current study, the hypothesis of a direct impact of the intervention delivery content can be suggested. The manipulation of the cognitive parenting variable of SEBs could have had a specific impact on parents' representation of their children's behavioral problems. As they felt more competent in their parenting role after the program, they may have improved their awareness of the need to give positive feedback, their persistence and understanding of the processes at stake in parentchild interactions, leading to changes in their negative view and representation of their children. This positive development may have led these parents to report lower child EB in the questionnaire-based assessment. As suggested in the "Confident Parents" study (Roskam et al., 2016), the improvement of SEBs may have contributed to modifying parents' representations of their children as measured by CBCL, even without or above any actual improvement in child observed behavior. Many parents came to the conclusion that part of their job as parents is to accept and adapt to their child as he or she is. When SEBs were combined with the manipulation of the behavioral parenting variable of ECPs, higher levels of positive behavior were observed among children in parent-child interactions. The cognitive-behavioral focus of the two-variable intervention may have led to the acquisition of new positive observed behaviors and concrete reactions in parents, resulting in turn in more positive behavior by the child towards the parent. Another complementary explanation of these results may be that children's behaviors reported with the CBCL questionnaire, i.e. attention problems and aggressiveness, or observed in the Crowell Procedure, i.e. positive affect, irritability, compliance, aggression, persistence and enthusiasm, are different from those considered in the correlations. The multi-method approach produces nuanced results regarding program efficacy. Whereas behavioral checklists such as the $\mathrm{CBCL}$ relate to symptoms of attention problems and aggressiveness that can be viewed in several daily settings, observational paradigms such as the Crowell Procedure relate to a micro-analytical assessment of behaviors displayed in a standardized setting where the child is interacting with his/her caregiver. The differences obtained in the current study question the relevance of efficacy studies that are based on a single method, usually parent reports. As no gold standard measure of child behavior exists, numerous studies recommend the use a multi-method design in line with the current results (Kraemer et al., 2003; Noordhof, Oldehinkel, Verhulst, \& Ormel, 2008; Roskam, Meunier, \& Stiévenart, 2013).

In sum, how can we summarize the contribution of the current study to the question of which and how many parenting variables should be addressed for effective interventions to reduce children's externalizing behavior? With regard to the nature of the variables manipulated, SEBs and ECPs seem to be good choices, since that they lead to effective behavioral changes in children. But the oneand two-format interventions cannot be considered as purely interchangeable, since their impact is different on EB reduction on the one hand and on observed behavior improvement on the other hand. To remain within the scope of the current study, we can simply conclude that the comparison of the one-variable intervention on SEBs vs. the two-variable intervention on ECPs and SEBs suggests differences in program efficacy. We can also conclude that compared to the wait list condition, the two-variable format combining SEBs and ECPs is slightly more effective than the onevariable format focusing on SEBs. Nevertheless, it is impossible to know if these conclusions would have been the same for isolated 
vs. combined manipulations of other variables, such as causal attributions or attentional bias as parental cognitions and monitoring or time-out practices as parental behaviors. Future studies should consider new comparisons of interventions, controlling for variations in the number and the nature of variables.

Two unexpected results emerged from the current study. First, manipulation check analyses demonstrated a similar improvement in SEBs in the two interventions, suggesting that the four-week stimulation (in the ECPs + SEBs intervention) and the eight-week stimulation (in the SEBs intervention) had the same impact. This unexpected result could perhaps be due to the timetable of the two-variable intervention. As a result of acquiring new positive reactions and behaviors regarding their children's emotions and practicing these new skills at home, parents experienced more and more positive interactions with their children. These took the form of positive accomplishment, regarded as the strongest source of SEBs. This may have put parents in a good position to benefit from the four-week stimulation of SEBs in the two-variable intervention. Rather than receiving positive feedback from the program leader in the absence of actual positive experience, as is sometimes the case in the one-variable intervention, parents in the two-variable intervention were able to increase their SEBs based on concrete positive interactions experienced with their children in the previous four weeks. Such an interpretation of the results contradicts research suggesting the need to target cognitive variables first in intervention programs (A. Ellis \& Bernard, 2006b). Previous research suggested that low SEBs may be an important initial obstacle to successful engagement in behavioral training for parents, and that SEBs manipulation should therefore be situated very early in the treatment or even prior to treatment in order to be as effective as possible (Bandura, Adams, Hardy, \& Howells, 1980; Stoolmiller, Duncan, Bank, \& Patterson, 1993). However, it was recognized that parents displaying low SEBs might become less resistant to treatment once they began experiencing positive parent-child interactions thanks to the parenting behaviors they had learned. Future investigations are needed to confirm the interpretation of these findings, in particular studies that counterbalance the order of stimulation of variables in two-variable interventions, i.e. ECPs + SEBs vs. SEBs + ECPs. At this stage, it may be suggested that the efficacy of parenting interventions differs not just according to variations in the number and nature of the variables manipulated but also according to the stimulation sequence. Some of the parenting variables may increase the benefits that can be obtained from stimulating another variable if they are stimulated first. Our results suggest that ECPs may be a good candidate for increasing the benefits of SEBs stimulation, leading to similar benefits after a four-week stimulation as after stimulation over eight weeks. Another interpretation of this unexpected result may be due to a widespread effect and to the interdependence between cognitions and behaviors in parenting. Indeed, results suggest that ECPs is a parenting variable which may cause positive cascading effect on parents' SEBs. And this widespread effect could be explained by the inevitable interaction between parent's cognitions and behaviors (Borkovec et al., 2002). Even if interdependence between these two systems is theoretically well documented, it remains impossible in practice to accurately control the way they influence each other in parenting intervention. Future studies are needed to address this question in micro-trials.

The second unexpected result was that the level of child EB was seen to significantly decrease in the wait list group. One explanation could simply be that children's behavior may improve over time irrespective of intervention especially during the younger years. Another explanation may be that at baseline, parents overreported their children's behavioral problems in order to convince therapists of the severity of the situation and make sure that they would be enrolled in the research program. Another explanation may relate to the unexpected impact of the first meeting between parent-child dyads and the program deliverers. Welcoming, empathetic listening and the completion of questionnaires regarding parents' role and children's temperament and behavior may not be as neutral as was thought. For some parents this was actually the first time they had been listened to and received support from professionals who recognized their children's difficult behavior and offered help. This first meeting actually activated the therapeutic alliance and may have helped reduce their extremely negative representation of their children's behavior. Again, this sustains the importance of a multi-method assessment strategy, which could protect against potential biases in parent-reported data (Tully \& Hunt, 2015).

While interesting in many ways, this study is by no means definitive. Several limitations have to be recognized and overcome in future studies. First, the use of a wait list design meant that we had no follow-up data in the control group. Spontaneous changes in parenting variables or child behavior cannot be completely excluded. However, this methodological choice was based on ethical reasons. A wait list was used in order to offer interventions to all participants whose children were objectively determined to have clinical levels of EB. An additional eight-week wait time would have been too long for families which had requested immediate assistance. Second, the limited number of parents in each intervention limited the statistical analyses that could be computed. In particular, we regret the absence of moderation analyses of child and parent gender and temperament in order to identify who benefited the most from the interventions. Third, it would have been interesting to analyze parenting practices reported by parents and to have observed parent behavior. This could have provided more insight into the relation between SEBs or ECPs and parenting behavior. It could have contributed to a mediation analysis between manipulated parenting variables and child behavior modification, as performed in other intervention studies (Gardner, Burton, \& Klimes, 2006) or micro-trials (Loop \& Roskam, 2016). Fourth, the cognitive dimension of ECPs and emotion dismissing practices were not taken into account in the current study. Parents' thoughts and feelings about emotions have been demonstrated to affect the way in which they respond to children's emotion (Eisenberg, Cumberland, \& Spinrad, 1998; Gottman et al., 1996). Despite the focused nature of micro-trials, it cannot completely be excluded that the cognitive dimension of ECPs has been affected in the ECPs + SEBs intervention. The importance of parents' dismissing practices have also been highlighted (Lunkenheimer et al., 2007). However, our study design was guided by our wish to manipulate parenting variables in isolation as well as the recommendation that parents beliefs and behaviors with regard to emotion coaching should be evaluated separately (Castro et al., 2015; Halberstadt et al., 2013). Fifth, even though measurement of parents' ECPs through emotional responsiveness in the Crowell Procedure gives important insights into how emotion socialization takes place in the parent-child interaction and is stronger than questionnaire data, it has to be regarded as a proxy for real-life interaction rather than a comprehensive assessment of parents' ECPs. However, the lack of validated observational measures of ECPs explained the need to use another closed variable. Finally, the generalization of these findings may be questioned. Most of the parents who participated to group interventions were above the average monthly income threshold, their level of education was high and most of them were two-parent families. Although interventions were free of charge and babysitting was offered, participating parents were not fully representative of the population from which they were drawn. It cannot be completely ruled out that results would be different with low SES parents. 
The current study has important clinical implications. First, evaluation of children's EB and therefore of interventions' efficacy should consider the observation of children's behavior in ecologically valid contexts. Second, treatment-providers should be encouraged to think carefully about the interventions they are employing, the processes they are aiming to alter, and the specific goals they are aiming to achieve (Burke \& Loeber, 2015). "Answering not just whether treatment change is produced, but how it is produced, is the cornerstone of advancing theoretical understanding about mechanisms of change" (La Greca, Silverman \& Lochman, 2009, p.377). Such a move towards tailored parenting interventions would also provide clinicians with the flexibility to adapt to variations in patients' problems, strengths, contexts or conditions.

\section{Acknowledgements}

This study received financial support as part of a coordinated research action on externalizing behavior (Convention ARC11/16038). It was also funded by the Belgian Fund for Scientific Research. We are grateful to the families who participated in the study and to our many sponsors for the gifts we offered our participants (Alice Délice, Martin's Spa, Tao, Libris Agora, Musée Hergé, Musée de Louvain-la-Neuve, Promosport, Bayard Milan). Thanks to research assistants for their support in coding videos.

\section{References}

Achenbach, T. M., \& Edelbrock, C. S. (1981). Behavioral problems and competencies reported by parents of normal and disturbed children aged four through sixteen. Monographs of the Society for Research in Child Development, 46, 1-82.

Achenbach, T. M., \& Rescorla, L. A. (2000a). ASEBA preschool forms \& profiles: An integrated system of multi-informant assessment. Aseba.

Achenbach, T. M., \& Rescorla, L. A. (2000b). Mental health practitioner's guide for the Achenbach system of empirically based assessment (ASEBA). Burlington: University of Vermont, Department of Psychiatry.

Anastasi, A., \& Urbina, S. (1997). Psychological testing (7th ed.). Englewood Cliffs, US: Prentice-Hall.

Ardelt, M., \& Eccles, J. S. (2001). Effects of mothers' parental efficacy beliefs and promotive parenting strategies on inner-city youth. Journal of Family Issues, 22, 944-972.

Bakermans-Kranenburg, M. J., Van Ijzendoorn, M., \& Juffer, F. (2008). Less is more: Meta-analytic arguments for the use of sensitivity-focused interventions. In F. Juffer, M. J. Bakermans-Kranenburg, \& M. H. van Ijzendoorn (Eds.), Promoting positive parenting: An attachment-based intervention (pp. 59-74). New York, NY: Taylor \& Francis Group/Lawrence Erlbaum Associates.

Bandura, A. (1977). Self-efficacy: Toward a unifying theory of behavioral change. Psychological Review, 84, 191-215.

Bandura, A. (1982). Self-efficacy mechanisms in human agency. American Psychologist, 37, 122-147.

Bandura, A. (1989). Regulation of cognitive process through perceived self-efficacy. Developmental Psychology, 25, 729-735.

Bandura, A., Adams, N. E., Hardy, A. B., \& Howells, G. N. (1980). Tests of the generality of self-efficacy theory. Cognitive Therapy and Research, 4, 39-66.

Belsky, J., \& Pluess, M. (2009). Beyond diathesis stress: Differential susceptibility to environmental influences. Psychological bulletin, 135(6), 885

Blandon, A. Y., Calkins, S. D., Keane, S. P., \& Brien, M. O. (2010). Contributions of child's physiology and maternal behavior to children's trajectories of temperamental reactivity. Developmental Psychology, 46, 1089-1102.

Borkovec, T. D., Newman, M. G., Pincus, A. L., \& Lytle, R. (2002). A component analysis of cognitive-behavioral therapy for generalized anxiety disorder and the role of interpersonal problems. Journal of Consulting and Clinical Psychology, $70,288$.

Brassart, E., \& Schelstraete, M.-A. (2015a). Enhancing the communication abilities of preschoolers at risk for behavior problems: Effectiveness of a parentimplemented language intervention. Infants \& Young Children, 28, 337-354.

Brassart, E., \& Schelstraete, M.-A. (2015b). Simplifying parental language or increasing verbal responsiveness, what is the most efficient way to enhance pre-schoolers' verbal interactions? Journal of Education and Training Studies, 3. 133-145.

Brody, G. H., Flor, D. L., \& Gibson, N. M. (1999). Linking maternal efficacy beliefs, developmental goals, parenting practices, and child competence in rural singleparent African American families. Child Development, 70, 1197-1208.

Burke, J. D., \& Loeber, R. (2015). The effectiveness of the stop now and plan (SNAP) program for boys at risk for violence and delinquency. Prevention Science, 16, $242-253$.
Buss, A. H., \& Plomin, R. (1984). Theory and measurement of EAS. Temperament: Early developing personality traits (pp. 98-130).

Campbell, S. B., Shaw, D. S., \& Gilliom, M. (2000). Early externalizing behavior problems: Toddlers and preschoolers at risk for later maladjustment. Development and Psychopathology, 12, 467-488.

Cassidy, J. (1994). Emotion regulation: Influences of attachment relationships. Monographs of the Society for Research in Child Development, 59, 228-283.

Castro, V. L., Halberstadt, A. G., Lozada, F. T., \& Craig, A. B. (2015). Parents' emotionrelated beliefs, behaviours, and skills predict Children's recognition of emotion. Infant and Child Development, 24, 1-22.

Cicchetti, D., \& Rogosch, F. A. (1996). Equifinality and multifinality in developmental psychopathology. Development and Psychopathology, 8, 597-600.

Coffee, P., \& Rees, T. (2011). When the chips are down: Effects of attributional feedback on self-efficacy and task performance following initial and repeated failure. Journal of Sports Sciences, 29, 235-245.

Coleman, P. K., \& Karraker, K. H. (1998). Self-efficacy and parenting quality: Findings and future applications. Developmental Review, 18, 47-85.

Coleman, P. K., \& Karraker, K. H. (2003). Maternal self-efficacy beliefs, competence in parenting, and toddlers' behavior and developmental status. Infant Mental Health Journal, 24, 126-148.

Cole, P. M., Michel, M. K., \& Teti, L. O. (1994). The development of emotion regulation and dysregulation: A clinical perspective. Monographs of the Society for Research in Child Development, 59, 73-100.

Crowell, J. A., \& Feldman, S. S. (1988). Mothers' internal models of relationships and children's behavioral and developmental status: A study of mother-child interaction. Child Development, 59, 1273-1285.

Crowell, J. A., \& Feldman, S. S. (1989). Assessment of mothers' working models of Relationships: Some clinical implications [Article] Infant Mental Health Journal, 10, 173-184.

Crowell, J. A., O'Connor, E., Wollmers, G., Sprafkin, J., \& Rao, U. (1991). Mothers' conceptualizations of parent-child relationships: Relation to mother-child interaction and child behavior problems. Development and Psychopathology, 3, $431-444$.

Cunningham, J. N., Kliewer, W., \& Garner, P. W. (2009). Emotion socialization, child emotion understanding and regulation, and adjustment in urban African American families: Differential associations across child gender. Development and Psychopathology, 21, 261.

Deković, M., Asscher, J., Hermanns, J., Reitz, E., Prinzie, P., \& Akker, A. (2010). Tracing changes in families who participated in the home-start parenting Program: Parental sense of competence as mechanism of change. Prevention Science, 11, 263-274.

Deković, M., Asscher, J. J., Manders, W. A., Prins, P. J., \& van der Laan, P. (2012). Within-intervention change: Mediators of intervention effects during multisystemic therapy. Journal of Consulting and Clinical Psychology, 80, 574.

Denham, S. A. (1997). "When I have a bad dream, mommy holds Me": Preschoolers' conceptions of emotions, parental socialisation, and emotional competence. International Journal of Behavioral Development, 20, 301-319.

Duncombe, M. E., Havighurst, S. S., Holland, K. A., \& Frankling, E. J. (2012). The contribution of parenting practices and parent emotion factors in children at risk for disruptive behavior disorders. Child Psychiatry and Human Development, 43, 715-733.

Dunsmore, J. C., Booker, J. A., \& Ollendick, T. H. (2013). Parental emotion coaching and child emotion regulation as protective factors for children with oppositional defiant disorder. Social Development, 22, 444-466.

Dunsmore, J. C., Booker, J. A., Ollendick, T. H., \& Greene, R. W. (2016). Emotion socialization in the context of risk and psychopathology: Maternal emotion coaching predicts better treatment outcomes for emotionally labile children with oppositional defiant disorder. Social Development, 25, 8-26.

Eisenberg, N., Cumberland, A., \& Spinrad, T. L. (1998). Parental socialization of emotion. Psychological Inquiry, 9, 241-273.

Ellis, B. H., Alisic, E., Reiss, A., Dishion, T., \& Fisher, P. A. (2014a). Emotion regulation among preschoolers on a continuum of risk: The role of maternal emotion coaching. Journal of Child and Family Studies, 23, 965-974.

Ellis, A., \& Bernard, M. E. (2006b). Rational emotive behavioral approaches to childhood disorders. New York.

Eyberg, S. M., Nelson, M. M., \& Boggs, S. R. (2008). Evidence-based psychosocial treatments for children and adolescents with disruptive behavior. Journal of Clinical Child \& Adolescent Psychology, 37, 215-237.

Fossum, S., Handegård, B. H. Adolfsen, F., Vis, S. A., \& Wynn, R. (2016). A metaanalysis of long-term outpatient treatment effects for children and adolescents with conduct problems. Journal of Child and Family Studies, 25, 15-29.

Furlong, M., McGilloway, S., Bywater, T., Hutchings, J., Smith, S. M., \& Donnelly, M. (2012). Behavioral and cognitive-behavioural group-based parenting interventions for early-onset conduct problems in children age 3-12 years. Cochrane Database of Systematic Reviews, 2.

Gardner, F., Burton, J., \& Klimes, I. (2006). Randomised controlled trial of a parenting intervention in the voluntary sector for reducing child conduct problems: Outcomes and mechanisms of change. Journal of Child Psychology and Psychiatry, $47,1123-1132$.

Gavița, O. A., Joyce, M. R., \& David, D. (2011). Cognitive behavioral parent programs for the treatment of child disruptive behavior. Journal of Cognitive Psychotherapy, 25, 240-256.

Gershoff, E. T., Grogan-Kaylor, A., Lansford, J. E., Chang, L., Zelli, A., DeaterDeckard, K., et al. (2010). Parent discipline practices in an international sample: Associations with child behaviors and moderation by perceived normativeness. 
Child Development, 81, 487-502.

Gershoff, E. T., Lansford, J. E., Sexton, H. R., Davis-Kean, P., \& Sameroff, A. J. (2012). Longitudinal links between spanking and Children's externalizing behaviors in a national sample of white, black, hispanic, and asian american families. Child Development, 83, 838-843.

Gottman, J. M., Katz, L. F., \& Hooven, C. (1996). Parental meta-emotion philosophy and the emotional life of families: Theoretical models and preliminary data. Journal of Family Psychology, 10, 243-268.

Graziano, P. A., Reavis, R. D., Keane, S. P., \& Calkins, S. D. (2007). The role of emotion regulation in children's early academic success. Journal of School Psychology, 45, 3-19.

La Greca, A. M., Silverman, W. K., \& Lochman, J. E. (2009). Moving beyond efficacy and effectiveness in child and adolescent intervention research. Journal of Consulting and Clinical Psychology, 77, 373-382.

Grolnick, W. S., Kurowski, C. O., McMenamy, J. M., Rivkin, I., \& Bridges, L. J. (1998). Mothers' strategies for regulating their toddlers' distress: Developmental changes and outcomes. Infant Behavior \& Development, 21, 437-450.

Halberstadt, A. G. (1991). Toward an ecology of expressiveness: Family socialization in particular and a model in general. Paris: Editions de la Maison des Sciences de l'Homme.

Halberstadt, A. G., Dunsmore, J. C., Bryant, A., Jr., Parker, A. E., Beale, K. S., \& Thompson, J. A. (2013). Development and validation of the parents' beliefs about Children's emotions questionnaire. Psychological Assessment, 25, 1195.

Havighurst, S. S., Wilson, K. R., Harley, A. E., Kehoe, C., Efron, D., \& Prior, M. R. (2013). "Tuning into Kids": Reducing young Children's behavior problems using an emotion coaching parenting program. Child Psychiatry \& Human Development, $44,247-264$.

Havighurst, S. S., Wilson, K. R., Harley, A. E., \& Prior, M. R. (2009). Tuning in to kids: An emotion-focused parenting program-initial findings from a community trial. Journal of Community Psychology, 37, 1008-1023.

Havighurst, S. S., Wilson, K. R., Harley, A. E., Prior, M. R., \& Kehoe, C. (2010). Tuning in to kids: Improving emotion socialization practices in parents of preschool children-findings from a community trial. Journal of Child Psychology and Psychiatry, 51, 1342-1350.

Howe, G. W., Beach, S. R., \& Brody, G. H. (2010). Microtrial methods for translating gene-environment dynamics into preventive interventions. Prevention Science, $11,343-354$.

Jones, T. L., \& Prinz, R. J. (2005). Potential roles of parental self-efficacy in parent and child adjustment: A review. Clinical Psychology Review, 25, 341-363.

Junttila, N., Vauras, M., \& Laakkonen, E. (2007). The role of parenting self-efficacy in childrenś social and academic behavior. European journal of psychology of education, 22, 41-61.

Katz, L. F., \& Gottman, J. M. (1997). Buffering children from marital conflict and dissolution. Journal of Clinical Child Psychology, 26, 157-171.

Katz, L. F., \& Windecker-Nelson, B. (2004). Parental meta-emotion philosophy in families with conduct-problem children: Links with peer relations. Journal of Abnormal Child Psychology, 32, 385-398.

Kazdin, A. E., \& Whitley, M. K. (2003). Treatment of parental stress to enhance therapeutic change among children referred for aggressive and antisocial behavior. Journal of Consulting and Clinical Psychology, 71, 504.

Keenan, K., \& Wakschlag, L. S. (2000). More than the terrible twos: The nature and severity of behavior problems in clinic-referred preschool children. Journal of Abnormal Child Psychology: An official publication of the International Society for Research in Child and Adolescent Psychopathology, 28, 33-46.

Kraemer, H. C., Measelle, J. R., Ablow, J. C., Essex, M. J., Boyce, W. T., \& Kupfer, D. J. (2003). A new approach to integrating data from multiple informants in psychiatric assessment and research: Mixing and matching contexts and perspectives. American Journal of Psychiatry, 160, 1566-1577.

Leerkes, E. M., \& Crockenberg, S. C. (2002). The development of maternal selfefficacy and its impact on maternal behavior. Infancy, 3, 227-247.

Leijten, P., Dishion, T. J., Thomaes, S., Raaijmakers, M. A., Orobio de Castro, B., \& Matthys, W. (2015). Bringing parenting interventions back to the Future: How randomized microtrials may benefit parenting intervention efficacy. Clinical Psychology: Science and Practice, 22, 47-57.

Loop, L., Mouton, B., Brassart, E., \& Roskam, I. (2016). The observation of child behavior during parent-child interaction: the psychometric properties of the Crowell procedure. Journal of Child and Family Studies, 1-11.

Loop, L., \& Roskam, I. (2016). Do children behave better when parents' emotion coaching practices are Stimulated? A micro-trial study. Journal of Child and Family Studies, 1-13.

Lundahl, B., Risser, H. J., \& Lovejoy, M. C. (2006). A meta-analysis of parent training: Moderators and follow-up effects. Clinical Psychology Review, 26, 86-104.

Lunkenheimer, E. S., Shields, A. M., \& Cortina, K. S. (2007). Parental emotion coaching and dismissing in family interaction. Social Development, 16, 232-248.

Ma, Y., Champion, C., \& Eisenberg, N. (2004). Emotion-related regulation: An emerging construct. Merrill-Palmer Quarterly, 50, 236-259.

Mackler, J. S., Kelleher, R. T., Shanahan, L., Calkins, S. D., Keane, S. P., \& O'Brien, M. (2015). Parenting stress, parental reactions, and externalizing behavior from ages 4 to 10. Journal of Marriage and Family, 77, 388-406.

Matheny, A. P., Wachs, T. D., Ludwig, J. L., \& Philips, K. (1995). Bringing order out of Chaos: Psychometric characteristics of the confusion, Hubbub, and order scale. Journal of Applied Developmental Psychology, 16, 429-444.

Menting, A. T., de Castro, B. O., \& Matthys, W. (2013). Effectiveness of the incredible years parent training to modify disruptive and prosocial child behavior: A metaanalytic review. Clinical Psychology Review, 33, 901-913.
Meunier, J. C., \& Roskam, I. (2009). Self-efficacy beliefs amongst parents of young children: Validation of a self-report measure. Journal of Child and Family Studies, $18,495-511$.

Meunier, J. C., Roskam, I., \& Browne, D. T. (2011). Relations between parenting and child behavior: Exploring the child's personality and parental self-efficacy as third variables. International Journal of Behavioral Development, 35, 246-259.

Meyer, S., Raikes, H., Virmani, E. A., Waters, S., \& Thompson, R. A. (2014). Parent emotion representations and the socialization of emotion regulation in the family. International Journal of Behavioral Development, 38, 164-173.

Morris, A. S., Silk, J. S., Morris, M. D. S., Steinberg, L., Aucoin, K. J., \& Keyes, A. W. (2011). The influence of mother-child emotion regulation strategies on Children's expression of anger and sadness. Developmental Psychology, 47, 213-225. http://dx.doi.org/10.1037/a0021021.

Mouton, B., Loop, L., Stievenart, M., \& Roskam, I. (2017). Meta-analytic review of parenting programs to reduce child externalizing behavior. Child and Family Behavior Therapy (in press).

Mouton, B., \& Roskam, I. (2015). Confident mothers, easier children: A quasiexperimental manipulation of mothers' self-efficacy. Journal of Child and Family Studies, 24, 2485-2495.

Nock, M. K. (2003). Progress review of the psychosocial treatment of child conduct problems. Clinical Psychology: Science and Practice, 10, 1-28.

Noordhof, A., Oldehinkel, A. J., Verhulst, F. C., \& Ormel, J. (2008). Optimal use of multi-informant data on co-occurrence of internalizing and externalizing problems: The TRAILS study. International Journal of Methods in Psychiatric Research, 17, 174-183.

Nowak, C., \& Heinrichs, N. (2008). A comprehensive meta-analysis of Triple PPositive Parenting Program using hierarchical linear modeling: Effectiveness and moderating variables. Clinical child and family psychology review, 11, $114-144$.

Oelofsen, N., \& Richardson, P. (2006). Sense of coherence and parenting stress in mothers and fathers of preschool children with developmental disability. Journal of Intellectual and developmental Disability, 31, 1-12.

Ollendick, T., \& King, N. (2012). Evidence-based treatments for children and adolescents: Issues and controversies. Child and adolescent therapy: Cognitivebehavioral procedures, 499-519.

Piquero, A. R., Farrington, D. P., Welsh, B. C., Tremblay, R., \& Jennings, W. G. (2009) Effects of early family/parent training programs on antisocial behavior and delinquency. Journal of Experimental Criminology, 5, 83-120.

Ramsden, S. R., \& Hubbard, J. A. (2002). Family expressiveness and parental emotion coaching: Their role in children's emotion regulation and aggression. Journal of Abnormal Child Psychology, 30, 657-667.

Renk, K. (2011). Mothers' perceptions of young children, parenting, and young Children's behavior problems. Child \& Family Behavior Therapy, 33, 123-138.

Roskam, I. (2015). Enhancing positive parenting through metacognition with the program 'lou \& us'. Journal of Child and Family Studies, 24, 2496-2507.

Roskam, I., Brassart, E., Houssa, M., Loop, L., Mouton, B., Volckaert, A., et al. (2016). Child-oriented or parent-oriented focused Intervention: Which is the better way to decrease Children's externalizing behaviors? Journal of Child and Family Studies, $1-15$.

Roskam, I., Brassart, E., Loop, L., Mouton, B., \& Schelstraete, M.-A. (2015). Stimulating parents' self-efficacy beliefs or verbal responsiveness: Which is the best way to decrease children's externalizing behaviors? Behaviour Research and Therapy, 72, 38-48.

Roskam, I., Brassart, E., Loop, L., Mouton, B., \& Schelstraete, M. A. (2016). Do parenting variables have specific or widespread impact on parenting covariates? The effects of manipulating self-efficacy or verbal responsiveness. Child \& Family Behavior Therapy, 38(2), 142-163.

Roskam, I., Meunier, J.-c., \& Stiévenart, M. (2013). The comparison and combination of multi-informant and multi-method data on preschoolers' externalizing behaviour. The International Journal of Educational and Psychological Assessment, 14, 79-93.

Rothbart, M., \& Bates, J. (2006). Temperament. In W. Damon, R. Lerner, \& N. Eisenberg (Eds.), Handbook of child psychology. Social, emotional, and personality development (Vol. 3, pp. 99-166). New York: Wiley.

Rouxel, G., Briec, J., Juhel, J., \& Le Maner-Idrissi, G. (2013). Factor structure of the EAS temperament survey (parental ratings) in two samples of children aged from 2 to 5 years and from 6 to 9 years. European Review of Applied Psychology, 63, $173-183$.

Rowe, D. C., \& Plomin, R. (1977). Temperament in early childhood. Journal of Personality Assessment, 41, 150-156.

Saarni, C. (1993). Socialization of emotion. New York, NY: Guilford Press.

Sanders, M. R. (1999). Triple P-Positive parenting program: Towards an empirically validated multilevel parenting and family support strategy for the prevention of behavior and emotional problems in children. Clinical Child and Family Psychology Review, 2, 71-90.

Sanders, M. R., Markie-Dadds, C., Tully, L., \& Bor, W. (2000). The triple P-positive parenting program: A comparison of enhanced, standard, and self-directed behavioral family intervention for parents of children with early onset conduct problems. Journal of Consulting and Clinical Psychology, 68, 624.

Sandler, I., Schoenfelder, E., Wolchik, S., \& MacKinnon, D. (2011). Long-term impact of prevention programs to promote effective parenting: Lasting effects but uncertain processes. Annual Review of Psychology, 62, 299.

Shipman, K. L., Schneider, R., Fitzgerald, M. M., Sims, C., Swisher, L., \& Edwards, A. (2007). Maternal emotion socialization in maltreating and non-maltreating Families: Implications for Children's emotion regulation. Social Development, 
$16,268-285$

Shumow, L., \& Lomax, R. (2002). Parental efficacy: Predictor of parenting behavior and adolescent outcomes. Parenting: Science and Practice, 2, 127-150.

Sofronoff, K., \& Farbotko, M. (2002). The effectiveness of parent management training to increase self-efficacy in parents of children with Asperger syndrome. Autism, 6, 271-286.

Stansbury, K., \& Sigman, M. (2000). Responses of preschoolers in two frustrating Episodes: Emergence of complex strategies for emotion regulation. The Journal of Genetic Psychology, 161, 182.

Stoolmiller, M., Duncan, T., Bank, L., \& Patterson, G. R. (1993). Some problems and solutions in the study of change: Significant patterns in client resistance. Journa of Consulting and Clinical Psychology, 61, 920.

Tully, L. \& Hunt, C. (2015). Brief parenting interventions for children at risk of externalizing behavior problems: A systematic review. Journal of Child and Family Studies, 1-15.

Valiente, C., Eisenberg, N., Shepard, S. A., Fabes, R. A., Cumberland, A. J., Losoya, S. H. et al. (2004). The relations of mothers' negative expressivity to Children's experience and expression of negative emotion. Journal of Applied Developmental Psychology, 25, 215-235.

Von Bertalanffy, L. (1968). General system theory. New York, 41973 (p. 40).

Wakschlag, L. S., Briggs-Gowan, M. J., Carter, A. S., Hill, C., Danis, B., Keenan, K., et al. (2007). A developmental framework for distinguishing disruptive behavior from normative misbehavior in preschool children. Journal of Child Psychology and Psychiatry, 48, 976-987.

Webster-Stratton, C. (2004). Quality training, supervision, ongoing monitoring, and agency support: Key ingredients to implementing The Incredible Years programs with fidelity. Treatment Description, 1-12.

Webster-Stratton, C., \& Hancock, L. (1998). Training for parents of young children with conduct problems: Content, methods, and therapeutic processes.

Webster-Stratton, C., \& Herman, K. C. (2010). Disseminating Incredible Years Series early-intervention programs: Integrating and sustaining services between school and home. Psychology in the Schools, 47, 36-54.

Webster-Stratton, C., \& Reid, M. (2010). Adapting the Incredible Years, an evidencebased parenting programme, for families involved in the child welfare system. Journal of Children's Services, 5, 25-42.

Webster-Stratton, C., \& Taylor, T. (2001). Nipping early risk factors in the bud: Preventing substance abuse, delinquency, and violence in adolescence through interventions targeted at young children (0-8 years). Prevention Science, 2, 165-192.

Wechsler, D. (2004). Wechsler preschool and primary scale of intelligence-third edition. French version. Paris: Centre de Psychologie Appliquée.

Zeman, J., \& Shipman, K. (1998). Influence of social context on children's affect regulation: A functionalist perspective. Journal of Nonverbal Behavior, 22, $141-165$.

Zimmer-Gembeck, M. J. \& Thomas, R. (2010). Parents, parenting and toddler adaptation: Evidence from a national longitudinal study of Australian children. Infant Behavior and Development, 33, 518-529.

Zimmermann, L. K., \& Stansbury, K. (2003). The influence of temperamental reactivity and situational context on the emotion-regulatory abilities of 3-year-old children. Journal of Genetic Psychology, 164, 389-409. 